\title{
Analysis of Young People's Physical Activity in East Java During the Covid-19 Pandemic
}

\author{
Ananda Riski Tarigan ${ }^{1, *}$ Bayu Agung Pramono ${ }^{1,}$ Yetty Septiani Mustar ${ }^{1,}$ Dewa \\ Wijaya $^{2,}$ Hafid Yusuf ${ }^{3}$
}

\author{
${ }^{1}$ Department of Spot Coaching Education, Universitas Negeri Surabaya, Indonesia \\ ${ }^{2}$ Department of Health Education and Recreation, Universitas Negeri Surabaya, Indonesia \\ ${ }^{3}$ IKIP Budi Utomo Malang, Indonesia \\ *Corresponding author. Email: tariganandarizky@gmail.com
}

\begin{abstract}
The COVID-19 pandemic has brought about significant changes in human movement activities. My activities, especially physical activity, are one of the non-pharmacological N77 treatments that can have a positive impact on humans. This study aims to determine the biological activities carried out by adolescents in East Java. One hundred twenty-eight youths in East Java aged 19-24 years participated in this study. This study uses a survey method in data collection. The questionnaire used the International Physical Activity Questionnaire (IPAQ). The results showed that, on average, the respondents did high and moderate-intensity physical activity three times a week. In comparison, the low intensity was carried out four times a week according to the duration of exercise that people did in 30 minutes of 60 minutes and only moved. An average of 2 hours per day for sitting activity. The conclusion in this study is that respondents combine physical exercise that aims to improve performance. This is very unprofitable if done during a pandemic if the respondent does not balance the training load and the volume of activity carried out with adequate rest and nutrition.
\end{abstract}
Keywords:
Physical
activity,
Intensity,
Covid-19,
$I P A Q$.

\section{INTRODUCTION}

The end of December was the worst month in China, with 41 cases of pneumonia recorded in Wuhan, China, and even the world [1]. Then gradually, Wuhan residents began to contract the virus now known as Covid19. It was discovered in 1965 as B814 [2]. As of March 23, 2021, the World Health Organization has confirmed more than 57 million infections and more than 1 million deaths in 121 countries [3]. In Indonesia alone, as of March 23, 2021, 1,471,225 cases and 39,865 confirmed deaths [4].

The first crucial step in HCV infection is the entry of host cells susceptible to specific receptors [5]. SARS-CoV-2, exclusively \& nonexclusively, suggested the immune system and is eliminated in the initial term; on the other hand, the secretion of inflammatory cytokines builds critical conditions resulting in multiorgan failure [6]. So patients with concomitant diseases are obliged to take all usual precautions to avoid being infected with SARS CoV-2, as they generally have the worst prognosis [7].
The virus attacks a person due to having a low immune system [6]. Proper regular exercise by combining the correct intensity will have a positive effect on the immune system. In addition, physical activity in some studies has positive results in the immune system [8]-[10]. Some world health organization's place physical activity as essential in maintaining health and fitness patterns and as one of the mandatory but controlled treatments in some patients, such as non-communicable diseases and even covid-19 patients. Studies have shown that an active lifestyle can activate the immune system [1], while obesity and related diseases can suppress immune system function [11], [12].

The urgency of this study is the number of covid-19 patients coming from young people aged 20 - 30 years even they ranked 2nd from the spread of covid-19 patients in Indonesia [4]. There needs to be an in-depth analysis of the physical activity profile carried out by these young people so that at this time, there are still many of them who become patients with COVID-19. This study focuses on physical activity as one of the indicators of the number of covid-19 patients in young people aged 20 - 22 years. 


\section{METHODS}

This research is descriptive. The data was taken from the online questionnaire to the sample cell. One hundred twenty-eight young people aged 19 - 24 years participated in this study. The questionnaire for this study was adopted in the International Physical Activity Questionnaire (IPAQ). The International Physical Activity Questionnaire is an international physical activity questionnaire developed to monitor an individual's physical activity. IPAQ devices at least have a good rating. Therefore, IPAQ as a whole has reasonable measurements to monitor the population level of physical activity in adults aged 18-65 [13]-[15].

\section{RESULTS}

Table 1 explains that the average age of respondents was 20 years, with an average weight of $61.65 \mathrm{~kg}$ and a resting pulse of 70.56 beats per second. When viewed from the flat result, it can be stated that all samples are in an ideal condition, which means that the model is in a fit condition by looking at a pulse below 100 beats per minute. The resting pulse rate is a measure of neurological fitness, so a lower resting pulse rate tends to be healthier.

Table 1. Respondent description

\begin{tabular}{|l|l|l|l|l|}
\hline & $\mathrm{N}$ & Min & Max & Mean \\
\hline Age (years) & 128 & 19 & 24 & 20,51 \\
\hline Weight (Kg) & 128 & 40 & 170 & 61,65 \\
\hline Pulse break (candy beat) & 128 & 48 & 96 & 70,56 \\
\hline
\end{tabular}

See (Table 2); it is known that as many as $78 \%$ of respondents complete a daily physical activity with strenuous physical activity at least three times a week, and as many as $2 \%$ of respondents do strenuous physical activity six times a week and seven times a week.

Table 2. Heavy physical activity

\begin{tabular}{|l|l|l|}
\hline Number of Activities Per Week & $\mathrm{n}$ & $\%$ \\
\hline One time a week & 23 & 18 \\
\hline Two times a week & 28 & 22 \\
\hline Three times a week & 49 & 38 \\
\hline Four times a week & 13 & 10 \\
\hline Five times a week & 6 & 5 \\
\hline Six times a week & 2 & 2 \\
\hline Seven times a week & 2 & 2 \\
\hline Never & 5 & 4 \\
\hline Total & 128 & 100 \\
\hline
\end{tabular}

Based on table 3, 38\% of the 128 respondents who applied the recommendation for physical exercise followed the reference in the ACSM, namely doing physical activity three times a week or at least 30 minutes every day. This can improve heart health, significantly reducing chronic non-communicable diseases and depression.

Table 3. Moderate physical activity

\begin{tabular}{|c|c|c|}
\hline Number of Activities Per Week & n & $\%$ \\
\hline One time a week & 24 & 19 \\
\hline Two times a week & 24 & 19 \\
\hline Three times a week & 31 & 24 \\
\hline Four times a week & 14 & 11 \\
\hline Five times a week & 15 & 12 \\
\hline Six times a week & 5 & 4 \\
\hline Seven times a week & 9 & 7 \\
\hline Never & 6 & 4 \\
\hline Total & 128 & 100 \\
\hline
\end{tabular}


As seen from table 4 , more than $50 \%$ of respondents do light physical activity four times a week. $34 \%$ of respondents never stop doing light physical activity for at least 45 minutes a week, and $6 \%$ of respondents do not do light physical activity.

Table 4. Light physical activity

\begin{tabular}{|l|l|l|}
\hline Number of Activities Per Week & $\mathrm{n}$ & 14 \\
\hline One time a week & 18 & 10 \\
\hline Two times a week & 13 & 17 \\
\hline Three times a week & 22 & 7 \\
\hline Four times a week & 9 & 9 \\
\hline Five times a week & 11 & 3 \\
\hline Six times a week & 4 & 34 \\
\hline Seven times a week & 43 & 6 \\
\hline Never & 8 & 100 \\
\hline Total & 128 & \multicolumn{2}{|c|}{} \\
\hline
\end{tabular}

From table 5, through the data in tables 2, 3, 4, it can be seen that the dominant respondents doing the highintensity physical activity are $38 \%$ of respondents and
$24 \%$ of moderate-intensity respondents every three times a week. In contrast, $34 \%$ of respondents do activities with low intensity seven times a week.

Table 5. Average training intensity

\begin{tabular}{|l|l|}
\hline Intensity & \\
\hline Vigorous & \\
\hline Moderate & \\
\hline Low &
\end{tabular}

The amazing thing is in table 6 where $89 \%$ of respondents are at most 2 hours not doing activities or just sitting studying, playing games or watching tv then doing physical activities either walking or just changing places or positions. This shows signs that almost all

Table 6. Sitting activity

\begin{tabular}{|c|c|c|}
\hline Time & $\mathrm{n}$ & $\%$ \\
\hline Never & 2 & 2 \\
\hline 30 minutes & 20 & 16 \\
\hline 45 minutes & 4 & 3 \\
\hline 1 hour & 16 & 12 \\
\hline 1 hour 30 minutes & 11 & 9 \\
\hline 1 hour 45 minutes & 6 & 5 \\
\hline 2 hours & 56 & 44 \\
\hline 3 hours & 3 & 2 \\
\hline 4 hours & 2 & 2 \\
\hline 5 hours & 5 & 4 \\
\hline 10 hours & 1 & 1 \\
\hline 12 hours & 2 & 2 \\
\hline Total & 128 & 100 \\
\hline
\end{tabular}

Based on table 7, it can be known that respondents with low physical activity in a week need an average of 1172.66 Mets and 118.43 KCal. while doing moderate

\section{Weekly}

3

3

7

respondents always move a maximum of every 2 hours. On the other hand, at 3 hours and above, $11 \%$ of respondents are sedentary or less active, increasing the risk of poor health such as obesity and cardiovascular disease.

physical activity, respondents required an average of 756.41 Mets and 826.29 Kcal per week. In contrast, high physical activity requires an average of 1468.69 
Mets and 1568.47 KCal per week. To get it for all respondents who performed physical activity in the past week, it took 3397.76 Mets and 3543.19 Kcal per week to gather energy in the body.

Table 7. Calories used

\begin{tabular}{|l|l|l|}
\hline Physical Activity Category & METS & Kcal \\
\hline Low & 1172,66 & 1148,43 \\
\hline Moderate & 756,41 & 826,29 \\
\hline High & 1468,69 & 1568,47 \\
\hline Total & 3397,76 & 3543,19 \\
\hline \multicolumn{2}{|c|}{$\begin{array}{l}\text { the effect on the increased risk of exposure to the virus } \\
\text { due to slow recovery. }\end{array}$} \\
\hline
\end{tabular}

The use of exercise is recommended for reducing infections, including viral lesions, and functions associated with the prevention of overweight, systemic inflammation, and non-communicable chronic diseases [16]. Physical activity exercises strengthen the immune system and adversely affect viral infections if performed beyond the body's capabilities.

From the results of the study, respondents should pay attention to the body's recovery process. The process of late recovery of the body will affect the health of the respiratory tract [17]. Respondents can perform active or passive recovery models to help the recovery process, as both have the same effect in improving the body's recovery process after 24 hours of physical exercise [17], [18].

Engaging in this study is that almost $90 \%$ of respondents combined high-intensity, moderate and mild physical activity patterns in a week. $10 \%$ of respondents even did high-intensity physical exercise for one week and added medium and light-intensity exercises. This will result in psychological stress, even in causing injury. This event will harm the immune system. Some researchers believe that intensity is the only significant variable. Still, others claim that the effects of training volume, intensity, frequency, exercise choice, exercise type, number of groups, frequency, rest, and pacing are equally important [19].

Data from the central COVID-19 management group states that 19 - 24 years old are the number 2 contributors in covid-19 infection patients [20]. Although it also provides data on the site that the above age clusters are not included in the top 3 sets of age, the most significant contributors of patients die from coronavirus infection.

A good activity recommended during the pandemic for children and adolescents is physical activity with a duration of at least 60 minutes with moderate to vigorous intensity [21]. In addition, a high-intensity workout that strengthens muscles and bones is recommended at least three times a week. So in the results of this study, there needs to be an excellent understanding for young people to understand the correct physical exercise patterns because for the pandemic period, physical activity is not only for the improvement of performance but must pay attention to
Other findings also concluded that one of the behavioral strategies to prevent and reduce COVID-19 infection is to regularly perform physical activities with moderate intensity and always maintain health protocols such as masks [22]. Although a large number of studies have shown that increasing the power of training suppresses the immune system and increases the rate of viral infection [23], two recent studies report that highintensity interval training (HIIT) does not have an inhibitory effect on immune function [24], [25].

Other articles also support that physical activity is a viable way to improve physical, heart, and health [26] in times of social isolation; recommended physical activities are aerobic exercise, resistance, breathing muscles, and yoga for healthy people. In patients with upper respiratory tract disease, patients with lower respiratory tract disease should restrict breathing muscles and yoga training [27].

Exercise patterns that use a combination of heavy, medium, and light exercises should pay attention to the design of nutrition due to physical activity. Fatigue will be fatal to the recovery process and support immune strengthening. Vitamins D and C, omega-3 fatty acids, and regular consumption of fruits and vegetables can be considered nutritional aids to support the immune system in those affected by COVID-19 [27].

The calories burned are also by the recommended calories burned per week, approximately 2000 Kcal [28]. Estimating the number of calories burned is essential because significant errors in weight-loss estimates can contribute to successful weight loss, which is often difficult to observe when trying through diet and exercise [29].

The exciting thing in this study is that respondents only allocated approximately 2 hours for prolonged sitting. This is very positive when associated with pandemic situations where all activities have space and time limitations. Lack of movement in more than 2 hours will significantly affect heart health and increase obesity [30]. Sedentary sitting is associated with workday burnout, decreased job satisfaction, high blood pressure, and symptoms of musculoskeletal disorders in the shoulders, waist, thighs, and knees of office workers [31]. 


\section{CONCLUSION}

This research provides an astonishing picture of the patterns of physical activity undertaken by young people. These results illustrate that they perform physical activity with a combination pattern of various exercise intensities, either high, medium, or low power, within one week. This combination exercise is quite good in the pre-pandemic period because the tired body will concentrate on the recovery process. Even so, during a pandemic, the body also conditions itself to maintain its condition from the attack of the coronavirus, which directly infects the body.

The number of young people infected with the virus is caused by the high activity carried out. Management of rest periods and balance of nutritional supplements may be the second factor that makes the recovery period slower, which results in the body's failure to defend itself from viral infections. This research needs to be developed further by adding a questionnaire related to rest time management and nutrition after physical exercise. These two indicators were not examined in this study because there were no questions in the IPAQ questionnaire. In the article, Dyah Mahendrasari argues that the mechanism of increasing or decreasing immunity during exercise can provide positive benefits in the long term and the need for vitamin supplements or adequate food.

\section{REFERENCES}

[1] R. Lu et al., "Genomic characterization and epidemiology of 2019 novel coronavirus: implications for virus origins and receptor binding," Lancet, vol. 395, no. 10224, pp. 565574, 2020, DOI: 10.1016/S0140-6736(20)302518.

[2] J. S. Kahn and K. McIntosh, "History and Recent Advances in Coronavirus Discovery," Pediatr. Infect. Dis. J., vol. 24, no. 11 SUPPL., pp. 223227 2005 ,

DOI: 10.1097/01.inf.0000188166.17324.60.

[3] World Health Organisation, "Information note on COVID-19 and NCDs,” 2020. [Online]. Available: https://www.who.int/who-documents-detail/covid19-and-ncds.

[4] KPCPEN, "Peta Sebaran COVID-19 Covid19," Komite Penanganan Covid-19 dan Pemulihan Ekonomi Nasional, 2021.

[5] Y. Yin and R. G. Wunderink, "MERS, SARS and other coronaviruses as causes of pneumonia," Respirology, vol. 23, no. 2, pp. 130-137, 2018, DOI: $10.1111 /$ resp. 13196.

[6] F. Yazdanpanah and M. R. Hamblin, "Since January 2020 Elsevier has created a COVID-19 resource center with free information in English and Mandarin on the novel coronavirus COVID19. The COVID-19 resource center is hosted on Elsevier Connect, the company's public news and information," no. January 2020.
[7] A. Sanyaolu et al., "Comorbidity and its Impact on Patients with COVID-19," SN Compr. Clin. Med., vol. 2, no. 8, pp. 1069-1076, 2020, DOI: 10.1007/s42399-020-00363-4.

[8] M. P. da Silveira, K. K. da Silva Fagundes, M. R. Bizuti, É. Starck, R. C. Rossi, and D. T. de Resende e Silva, "Physical exercise as a tool to help the immune system against COVID-19: an integrative review of the current literature," Clin. Exp. Med., vol. 2019, pp. 1-14, 2020, DOI: 10.1007/s10238-020-00650-3.

[9] B. Gavilán-Carrera et al., "Association of objectively measured physical activity and sedentary time with health-related quality of life in women with fibromyalgia: The al-Ándalus project," J. Sport Heal. Sci., vol. 8, no. 3, pp. 258 266, 2019, DOI: 10.1016/j.jshs.2018.07.001.

[10] D. C. Nieman and S. H. Mitmesser, "Potential impact of nutrition on immune system recovery from heavy exertion: A metabolomics perspective," Nutrients, vol. 9, no. 5, 2017, DOI: 10.3390/nu9050513.

[11] K. Suzuki, "Chronic inflammation as an immunological abnormality and effectiveness of exercise," Biomolecules, vol. 9, no. 6, pp. 3-7, 2019, DOI: 10.3390/biom9060223.

[12] F. P. De Heredia, S. Gómez-Martínez, and A. Marcos, "Chronic and degenerative diseases: Obesity, inflammation and the immune system," Proc. Nutr. Soc., vol. 71, no. 2, pp. 332-338, 2012, doi: $10.1017 / \mathrm{S} 0029665112000092$.

[13] C. L. Craig et al., "International physical activity questionnaire: 12-Country reliability and validity," Med. Sci. Sports Exerc., vol. 35, no. 8, pp. 13811395, 2003, DOI: 10.1249/01.MSS.0000078924.61453.FB.

[14] R. Maddison et al., "International physical activity questionnaire (IPAQ) and New Zealand physical activity questionnaire (NZPAQ): A doubly labeled water validation," Int. J. Behav. Nutr. Phys. Act., vol. 4, pp. 1-9, 2007, DOI: 10.1186/1479-5868-462.

[15] L. Frehlich, C. Friedenreich, A. Nettel-Aguirre, F. A. Uribe, and G. McCormack, "Reliability of an International Physical Activity Questionnaire (IPAQ) Modified to Capture Neighbourhoodspecific Physical Activity ( poster )," J. Transp. Heal., vol. 7, no. 2017, pp. S14-S15, 2017, DOI: 10.1016/j.jth.2017.11.024.

[16] D. R. Laddu, C. J. Lavie, S. A. Phillips, and R. Arena, "Physical activity for immunity protection: Inoculating populations with healthy living medicine in preparation for the next pandemic," Prog. Cardiovasc. Dis., no. xxxx, pp. 4-6, 2020, doi: 10.1016/j.pcad.2020.04.006.

[17] B. Van Hooren and J. M. Peake, "Do We Need a Cool-Down After Exercise? A Narrative Review of the Psychophysiological Effects and the Effects on Performance, Injuries and the Long-Term Adaptive Response," Sport. Med., vol. 48, no. 7, 
pp. 1575-1595, 2018, DOI: 10.1007/s40279-0180916-2.

[18] J. de Andrade Bezerra, A. C. M. de Castro, S. V. A. Melo, F. S. B. Martins, R. P. M. Silva, and J. A. R. dos Santo, "Passive, Active, and Cryotherapy Post-Match Recovery Strategies Induce Similar Immunological Response in Soccer Players," Int. J. Sport. Sci., vol. 4, no. 6A, pp. 12-18, 2014, DOI: 10.5923/s.sports.201401.02.

[19] J. Wang, S. Liu, G. Li, and J. Xiao, "Exercise Regulates the Immune System," Adv. Exp. Med. Biol., vol. 1228, pp. 395-408, 2020, DOI: 10.1007/978-981-15-1792-1_27.

[20] KPCPEN, "Peta Sebaran COVID-19 _ Covid19," Komite Penanganan Covid-19 dan Pemulihan Ekonomi Nasional. p. 1, 2021.

[21] D. Riebe, J. Ehrman, G. Liguori, and M. Magal, ACSM's Guidelines for Exercise Testing and Prescription. 2018.

[22] N. T. Hutchinson, A. Steelman, and J. A. Woods, "Behavioral strategies to prevent and mitigate COVID-19 infection," Sport. Med. Heal. Sci., vol. 2, no. 3, pp. 115-125, 2020, DOI: 10.1016/j.smhs.2020.09.001.

[23] E. M. Paolucci, D. Loukov, D. M. E. Bowdish, and J. J. Heisz, "Exercise reduces depression and inflammation but intensity matters," Biol. Psychol., vol. 133, pp. 79-84, Mar. 2018, DOI: 10.1016/J.BIOPSYCHO.2018.01.015.

[24] C. Monje, I. Rada, M. Castro-Sepulveda, L. Peñailillo, L. Deldicque, and H. Zbinden-Foncea, "Effects of a high-intensity interval session on mucosal immune function and salivary hormones in male and female endurance athletes," J. Sport. Sci. Med., vol. 19, no. 2, pp. 436-443, 2020.

[25] D. P. Born, C. Zinner, and B. Sperlich, "The mucosal immune function is not compromised during a period of high-intensity interval training.
Is it time to reconsider an old assumption?" Front. Physiol., vol. 8, no. JUL, pp. 1-9, 2017, DOI: 10.3389/fphys.2017.00485.

[26] R. A. L. De Sousa, A. C. Improta-Caria, R. ArasJúnior, E. M. de Oliveira, Ú. P. R. Soci, and R. C. Casillas, "Physical exercise effects on the brain during COVID-19 pandemic: links between mental and cardiovascular health," Neurol. Sci., vol. 42, no. 4, pp. 1325-1334, 2021, DOI: $10.1007 / \mathrm{s} 10072-$ 021-05082-9.

[27] K. Khoramipour, A. Basereh, A. A. Hekmatikar, L. Castell, R. T. Ruhee, and K. Suzuki, "Physical activity and nutrition guidelines to help with the fight against COVID-19," J. Sports Sci., vol. 39, no. 1 , pp. 101-107, 2021, DOI: 10.1080/02640414.2020.1807089.

[28] J. E. Donnelly, S. N. Blair, J. M. Jakicic, M. M. Manore, J. W. Rankin, and B. K. Smith, "Appropriate physical activity intervention strategies for weight loss and prevention of weight regain for adults," Med. Sci. Sports Exerc., vol. 41, no. 2, pp. 459-471, 2009, DOI: 10.1249/MSS.0b013e3181949333.

[29] R. E. Brown et al., "Calorie Estimation in Adults Differing in Body Weight Class and Weight Loss Status," Med. Sci. Sports Exerc., vol. 48, no. 3, pp. 521-526, 2016, DOI: 10.1249/MSS.0000000000000796.

[30] T. E. Vanhecke, B. A. Franklin, W. M. Miller, A. T. Dejong, C. J. Coleman, and P. A. McCullough, "Cardiorespiratory fitness and sedentary lifestyle in the morbidly obese," Clin. Cardiol., vol. 32, no. 3, pp. 121-124, 2009, DOI: 10.1002/clc.20458.

[31] H. Daneshmandi, A. Choobineh, H. Ghaem, and M. Karimi, "Adverse Effects of Prolonged Sitting Behavior on the General Health of Office Workers," J. Lifestyle Med., vol. 7, no. 2, pp. 6975, 2017, DOI: 10.15280/jlm.2017.7.2.69. 